Original Research Paper

\title{
Respiratory Health of Male Steel Workers in the Eastern Coast of Peninsular Malaysia
}

\author{
${ }^{1,3}$ Nurul Ainun Hamzah, ${ }^{2}$ Shamsul Bahri Mohd Tamrin and ${ }^{1}$ Noor Hassim Ismail \\ ${ }^{1}$ Department of Community Health, Faculty of Medicine, Universiti Kebangsaan Malaysia, Malaysia \\ ${ }^{2}$ Department of Environmental and Occupational Health, \\ Faculty of Medicine and Health Sciences, Universiti Putra Malaysia, Malaysia \\ ${ }^{3}$ Division of Environmental and Occupational Health, School of Health Sciences, Universiti Sains Malaysia, Malaysia
}

\author{
Article history \\ Received: 26-04-2015 \\ Revised: 21-06-2015 \\ Accepted: 24-06-2015 \\ Corresponding Author: \\ Nurul Ainun Hamzah \\ Department of Community \\ Health, Faculty of Medicine, \\ Universiti Kebangsaan \\ Malaysia \\ E-mail: a_nurul81@yahoo.com
}

\begin{abstract}
A cross sectional study was carried out to determine the prevalence of respiratory symptoms and associated factors with respiratory health among male steel workers. A total of 424 male workers in the steel production plant were recruited using a stratified random sampling. Subjects were interviewed regarding respiratory symptoms using a British Medical Research Council (BMRC) Questionnaire on respiratory symptoms and were examined their lung function using spirometry. Prevalence of chronic cough, chronic phlegm, chest tightness and shortness of breath were $35.8,32.8,23.4$ and $22.4 \%$, respectively. Age, duration employment and smoking were among the factors associated with respiratory symptoms $(p<0.05)$. Forced Expiratory in 1 sec $\left(\mathrm{FEV}_{1}\right)$ and $\% \mathrm{FEV}_{1} / \mathrm{FVC}$ of workers were significantly reduced as compared to the healthy population $(p<0.05)$. The effect of cigarette on $\mathrm{FEV}_{1}$ was shown among the current smokers $(\beta=-0.099, p<0.05)$. Level of dustiness was significantly reduced the FVC $(\beta=-0.047, p<0.05)$ while duration of work was significantly reduced the $\% \mathrm{FEV}_{1} / \mathrm{FVC}(\beta=-0.214, \mathrm{p}<0.01)$. Lung function test revealed some degree of impairment as compared to healthy population and smoking also had an additive effect on respiratory health, thus required further extensive epidemiological and pathological studies for the health and safety of the steel mill workers.
\end{abstract}

Keywords: Respiratory Symptoms, Lung Function, Steel Workers

\section{Introduction}

Exposure to airborne contaminants in metallurgical industry is one of the a etiological factors in the occurrence of pathological changes in respiratory pathways. A number of studies have been reported that occupational dust exposure in steel manufacturing may lead to pulmonary abnormalities (Bogadi-Šare, 1990; Kolarzyk et al., 2000; Chen et al., 2006). Steel workers are potentially exposed to inorganic dust and toxic gaseous that may have adverse effects to respiratory health. They also have higher risk of having respiratory symptoms and life-long chronic obstructive airways diseases including asthma, COPD, pneumoconiosis and cancers (Kayhan et al., 2013; Bala and Tabaku, 2010; Johnson et al., 1985; Huvinen and Pukkala, 2013).

Most of the studies were carried out in developed countries, whereas in Malaysia very limited data is available in occupational and safety issues involving steel industry. Preliminary studies reported that steel workers had a high prevalence of respiratory symptoms and lung function impairment (Azwan et al., 2006; Nurul et al., 2006). Therefore, it is essential to investigate the associated factors such as demographic, employment, smoking, as well as occupational and safety practices particularly the usage of mask to respiratory health. The aim of this study was to determine the prevalence of respiratory symptoms and their associated factors, to compare the lung function with Malaysian healthy population and to determine the contributing factors to lung function among steel workers.

\section{Material and Methods}

The cross sectional study was in Terengganu, the eastern region of Peninsular Malaysia. This 30-year old factory is the only steel factory operating in the eastern region during the study period. This steel factory 
employs more than 1000 workers at production line; only 424 were recruited randomly using a stratified random sampling. The strata were formed based on work units. A sample from each stratum was based on these criteria: Male, age from 18 to 56 years old and at least one year duration of work. Ninety seven percent of them completed the questionnaire.

\section{Measurement of Respiratory Health}

The subjects were interviewed using a modified version of the British Medical Research Council Questionnaire (BMRC) questionnaire translated into Malay, was pre-tested and administered by interviewers (MRC, 1966). The questionnaire was pertaining to the respiratory symptoms, past medical history, smoking status, occupational history, level of dustiness and frequency usage of mask.

Chronic cough refers to cough symptoms for at least three days a week for at least three months a year for two consecutive years or more. Chronic phlegm refers to phlegm production for at least three days a week for at least three months a year for two consecutive years or more. Chest tightness is defined as discomfort or pain anywhere along the front of body between the neck and upper abdomen and shortness of breath as breathlessness when hurrying on the level or walking up a slight incline.

Past respiratory illnesses are defined as any history of respiratory diseases including bronchitis, pneumonia, chronic bronchitis, emphysema, asthma, pleurisies, pulmonary tuberculosis or any chest operation confirmed by medical doctors and pasty dusty occupations as past dust exposure for more than two years before joining the company.

The following definitions of smoking were used: Non-smokers never smoke any cigarette or tobacco in a lifetime; ex-smokers were those who had stopped smoking at least 6 months before testing and everybody else were classified as being current smokers. The subjects were grouped into non-current smokers and current smokers using the current smoker variable (yes/no). Lifetime cigarette consumption was coded and analyzed as a continuous variable-cigarette equivalent (packs per day multiplied by number of years smoked). The frequency of wearing mask during the entire work shift was divided into three levels corresponding to often, seldom and always. Levels of dustiness were based on working section (high or low exposure).

Lung function was measured with a spirometer (Model Spirolab MIR). A total of 402 workers performed spirometric testing in accordance to the requirements of American Thoracic Society (ATS). However, those who were unable to produce acceptable spirograms meeting the American Thoracic Society criteria $(\mathrm{N}=22)$ were excluded from the analysis to enhance the valid contrast (ATS). Each subject was asked to inhale deeply in standing position with the nose clamped, blowing rapidly and completely as possible. The procedure was explained and demonstrated to each subject. At least three measurements were taken for each subject. Only one best flow was recorded and printed. Results were automatically corrected to body temperature. Height and weight were recorded to the nearest $0.5 \mathrm{~cm}$ and $0.5 \mathrm{~kg}$, respectively.

\section{Statistical Analysis}

Data analyses were done using IBM Statistical Package for Social Science (SPSS) version 20. One sample $t$-test was used to compare mean of lung function parameter to the healthy Malaysia standard (Singh et al., 1993). Sample proportions were compared by chi square test. Multiple linear Regression (MLR) analysis was applied to identify the factors associated with lung function values. The outcome variables analyzed were Forced Vital Capacity (FVC), Forced Expiratory Volume in One Second $\left(\mathrm{FEV}_{1}\right)$ and $\left.\% \mathrm{FEV}_{1} / \mathrm{FVC}\right)$. The significant level used for evaluating the test of significance was set at $\mathrm{p}<0.05$.

\section{Ethical Considerations}

This study was approved by the Research and Ethics Committee, UKM Medical Center, reference number FF055-2013 dated on 6th February 2013. All data were kept confidential throughout the study.

\section{Results}

\section{Background of the Respondents}

Four hundred and two male Malay steel workers with mean age of 36.8 years \pm 8.81 were assessed. Mean duration of employment was 12.2 years \pm 8.23 years of work. Forty percent of the workers were more than 40 years old. Fifty four percent of the workers were current smokers. Mean cigarette equivalent was $9.9 \pm 9.71 \mathrm{pack} / \mathrm{years}$. Prior to joining this company, $5.2 \%$ had been exposed to occupationally dusty environments and $4.2 \%$ had a history of respiratory diseases. Majority of the workers (65.7\%) did not wear mask frequently during the working period.

\section{Respiratory Symptoms}

Symptoms were grouped into 4 main categories namely chronic cough, chronic phlegm, chest tightness and shortness of breath. These symptoms were based on their experience in the last 12 months. Chronic cough was the common symptoms (35.8\%) claimed by the workers, followed by chronic phlegm $(32.8 \%)$, chest of tightness $(23.4 \%)$ and shortness of breath (22.4\%) (Fig. 1). 
Table 1. Relationship between each respiratory symptom with level of dustiness, age, duration of employment and smoking status

\begin{tabular}{|c|c|c|c|c|}
\hline \multirow[b]{2}{*}{ Factors } & \multicolumn{2}{|c|}{ Respiratory symptom, n (\%) } & \multirow[b]{2}{*}{$\mathrm{P}$} & \multirow[b]{2}{*}{ POR $(95 \% \mathrm{CI})$} \\
\hline & YES & NO & & \\
\hline \multicolumn{5}{|c|}{ Chronic cough } \\
\hline \multicolumn{5}{|l|}{ Level of dustiness } \\
\hline High & $75(38.1)$ & $122(61.9)$ & 0.356 & 1.21 \\
\hline Low & $69(33.7)$ & $136(66.8)$ & & $(0.79-1.85)$ \\
\hline \multicolumn{5}{|l|}{ Age } \\
\hline$\geq 40$ years & $71(43.3)$ & $93(56.7)$ & $0.009^{*}$ & 1.73 \\
\hline$<40$ years & $73(30.7)$ & $165(69.3)$ & & $(1.14-2.61)$ \\
\hline \multicolumn{5}{|c|}{ Duration of employment } \\
\hline$\geq 10$ years & $83(38.2)$ & $134(61.8)$ & 0.272 & 1.26 \\
\hline$<10$ years & $61(33.0)$ & $124(67.0)$ & & $(0.84-1.90)$ \\
\hline \multicolumn{5}{|l|}{ Smoking } \\
\hline Current smokers & $86(39.4)$ & $132(60.6)$ & 0.099 & 1.42 \\
\hline Non current smokers & $58(31.5)$ & $126(68.5)$ & & $(0.94-2.14)$ \\
\hline \multicolumn{5}{|c|}{ Chronic Phlegm } \\
\hline \multicolumn{5}{|l|}{ Level of dustiness } \\
\hline High & $61(29.8)$ & $144(70.2)$ & 0.18 & 1.33 \\
\hline Low & $71(36.0)$ & $126(64.0)$ & & $(0.85-2.01)$ \\
\hline \multicolumn{5}{|l|}{ Age } \\
\hline$\geq 40$ years & $60(36.3)$ & $104(63.4)$ & 0.184 & 1.33 \\
\hline$<40$ years & $72(30.3)$ & $106(69.7)$ & & $(0.87-2.03)$ \\
\hline \multicolumn{5}{|c|}{ Duration of employment } \\
\hline$\geq 10$ years & $81(37.3)$ & $136(62.7)$ & $0.038^{*}$ & 1.56 \\
\hline$<10$ years & $51(27.6)$ & $134(72.4)$ & & $(1.02-2.39)$ \\
\hline \multicolumn{5}{|l|}{ Smoking } \\
\hline Current smokers & $61(33.2)$ & $123(66.8)$ & 0.901 & 1.03 \\
\hline \multirow[t]{2}{*}{ Non current smokers } & $71(32.6)$ & $147(67.4)$ & & $(0.84-1.23)$ \\
\hline & \multicolumn{4}{|c|}{ Chest tightness } \\
\hline \multicolumn{5}{|l|}{ Level of dustiness } \\
\hline High & $50(24.4)$ & $155(75.6)$ & 0.626 & 1.12 \\
\hline \multirow{2}{*}{\multicolumn{5}{|c|}{$\begin{array}{l}\text { Low } \\
\text { Age }\end{array}$}} \\
\hline & & & & \\
\hline$\geq 40$ years & $44(26.8)$ & $120(73.2)$ & 0.175 & 1.38 \\
\hline$<40$ years & $50(21.0)$ & $188(79.0)$ & & $(0.87-2.20)$ \\
\hline \multicolumn{5}{|c|}{ Duration of employment } \\
\hline$\geq 10$ years & $53(24.4)$ & $164(75.6)$ & 0.593 & 1.14 \\
\hline$<10$ years & $41(22.2)$ & $144(77.8)$ & & $(0.71-1.81)$ \\
\hline \multicolumn{5}{|l|}{ Smoking } \\
\hline Current smokers & $58(26.6)$ & $160(73.4)$ & 0.097 & 1.49 \\
\hline Non current smokers & $36(19.6)$ & $148(80.4)$ & & $(0.93-2.39)$ \\
\hline & & reath & & \\
\hline Level of dustiness & & & & \\
\hline High & $46(22.4)$ & $159(77.6)$ & 0.98 & 1.01 \\
\hline Low & $44(22.3)$ & $153(77.7)$ & & $(0.63-1.61)$ \\
\hline Age & & & & \\
\hline$\geq 40$ years & $44(26.8)$ & $120(73.2)$ & 0.076 & 1.53 \\
\hline$<40$ years & $46(19.3)$ & $192(80.7)$ & & $(0.96-2.45)$ \\
\hline Duration of employm & & & & \\
\hline$\geq 10$ years & $54(24.9)$ & $163(75.1)$ & 0.193 & 1.37 \\
\hline$<10$ years & $36(19.5)$ & $149(80.5)$ & & $(0.85-2.21)$ \\
\hline Smoking & & & & \\
\hline Current smokers & $59(27.1)$ & $159(72.9)$ & $0.014 *$ & 1.83 \\
\hline Non current smokers & $31(16.8)$ & $153(83.2)$ & & $(1.12-2.98)$ \\
\hline
\end{tabular}

POR: Prevalence odds ratio calculations $(95 \% \mathrm{CI}), *$ Significance at $\mathrm{P}$ or below than 0.05

Using a chi square test

Each of the respiratory symptoms was analyzed for any relationship with age group, duration of employment, smoking and level of dustiness by univariate analysis. It has been revealed that age $(\mathrm{POR}=1.73, \mathrm{p}=0.009)$ had $\mathrm{a}$ significant relationship with chronic cough, duration of work $(\mathrm{POR}=1.56, \mathrm{p}=0.038)$ had a relationship with chronic phlegm, whereas smoking $(\mathrm{POR}=1.83, \mathrm{p}=0.014)$ was found significantly related to shortness of breath. However, level of dustiness had no relationship with all of the reported respiratory symptoms (Table 1). 
Table 2. The pattern of $\mathrm{FEV}_{1}$ and FVC

\begin{tabular}{lcclll}
\hline Parameters & Steel workers & Malaysia healthy population & Mean difference & t-stat (df) & $\mathrm{p}$ value \\
\hline FEV & & 3.11 & -0.200 & $-8.61(401)$ & $\mathrm{p}<0.001^{*}$ \\
$\mathrm{FVC}$ & 2.91 & 3.49 & -0.037 & $-1.42(401)$ & $\mathrm{p}=0.158$ \\
FEV $_{1} /$ FVC (\%) & 3.45 & 89.11 & -0.477 & $-17.20(401)$ & $\mathrm{p}<0.001^{*}$ \\
\hline
\end{tabular}

*Significant at $\mathrm{p}<0.05$, Using a Chi square test

Table 3. Predictors of lung function values in simple and multiple linear regression

\begin{tabular}{|c|c|c|c|c|}
\hline \multirow[b]{2}{*}{ Predictors } & \multicolumn{2}{|c|}{ Current smokers $(\mathrm{N}=218)$} & \multicolumn{2}{|c|}{ Non smokers $(\mathrm{N}=184)$} \\
\hline & SLR & MLR & SLR & MLR \\
\hline \multicolumn{5}{|c|}{$\mathrm{FEV}_{1}$ (Litre) } \\
\hline Constant & - & $2.776^{* *}$ & - & $2.857 * *$ \\
\hline Age (year) & $-0.031 * *$ & $-0.026 * *$ & $-0.031 * *$ & $-0.024 * *$ \\
\hline BMI $\left(\mathrm{kg} / \mathrm{ms}^{2}\right)$ & $-0.022 * *$ & $-0.010^{*}$ & $-0.015^{*}$ & $-0.015^{*}$ \\
\hline Duration of employment (year) & $-0.030 * *$ & NS & $-0.025 * *$ & NS \\
\hline Cigarette equivalent (pack/year) ${ }^{\mathrm{a}}$ & $-0.276 * *$ & $-0.099 *$ & - & - \\
\hline Past dusty occupations (yes) & -0.678 & NS & -0.452 & NS \\
\hline Past respiratory illnesses (yes) & -0.128 & NS & -0.023 & NS \\
\hline Level of dustiness (grades) & -0.005 & NS & -0.005 & NS \\
\hline Frequently wearing mask (yes) & 0.096 & NS & 0.069 & NS \\
\hline $\mathrm{R}$ & - & 0.727 & - & 0.775 \\
\hline \multicolumn{5}{|c|}{ FVC (Litre) } \\
\hline Constant & - & $3.174 * *$ & - & $3.367 * *$ \\
\hline Age (year) & $-0.030 * *$ & $-0.023 * *$ & $-0.034 * *$ & $-0.032 * *$ \\
\hline BMI $\left(\mathrm{kg} / \mathrm{ms}^{2}\right)$ & $-0.027 * *$ & $-0.014^{*}$ & $-0.017^{*}$ & $-0.017^{*}$ \\
\hline Duration of employment (year) & $-0.027 * *$ & NS & $-0.028 * *$ & NS \\
\hline Cigarette equivalent (pack/year) ${ }^{\mathrm{a}}$ & $-0.326 * *$ & NS & - & - \\
\hline Past dusty occupations (yes) & 0.200 & NS & -0.663 & NS \\
\hline Past respiratory illnesses (yes) & -0.812 & NS & -0.155 & NS \\
\hline Level of dustiness (grades) & $-0.054 *$ & $-0.047 *$ & -0.013 & NS \\
\hline Frequently wearing mask (yes) & 0.156 & $0.123^{*}$ & 0.053 & NS \\
\hline $\mathrm{R}$ & - & 0.733 & - & 0.781 \\
\hline \multicolumn{5}{|c|}{$\mathrm{FEV}_{1} / \mathrm{FVC}(\%)$} \\
\hline Constant & - & $82.83 * *$ & - & $84.62 * *$ \\
\hline Age (vear) & $-0.184 * *$ & $-0.144^{*}$ & $-0.060 *$ & NS \\
\hline BMI $\left(\mathrm{kg} / \mathrm{ms}^{2}\right)$ & -0.010 & NS & -0.007 & NS \\
\hline Duration of employment (year) & $-0.225 * *$ & $-0.214 * *$ & -0.042 & NS \\
\hline Cigarette equivalent (pack/year) ${ }^{\mathrm{a}}$ & $-0.091 *$ & NS & - & - \\
\hline Past dusty occupations (yes) & -0.122 & NS & -0.392 & NS \\
\hline Past respiratory illnesses (yes) & -0.761 & $-0.956 * *$ & $-2.753^{*}$ & NS \\
\hline Level of dustiness (grades) & $-1.050^{*}$ & NS & -0.127 & NS \\
\hline Frequently wearing mask (yes) & 1.166 & NS & 0.586 & NS \\
\hline $\mathrm{R}$ & - & 0.345 & - & 0.223 \\
\hline
\end{tabular}

Abbreviations: BMI; Body Mass Index, NS, Not significant

SLR; Simple Linear Regression, MLR; Multiple Linear Regression, R Multiple correlation coefficient

${ }^{a}$ Logarithm transformation before analysis

$*$ Significance at $\mathrm{p} \leq 0.05,{ }^{*}$ significance at $\mathrm{p} \leq 0.01$

\section{Lung Function}

Mean value for Forced Expiratory Volume in One Second $\left(\mathrm{FEV}_{1}\right)$ and Force Vital Capacity (FVC) was low as compared to the value of healthy Malaysia population. The difference of $\mathrm{FEV}_{1}(\mathrm{p}<0.001)$ and $\% \mathrm{FEV}_{1} / \mathrm{FVC}$ $(p<0.001)$ were significant from value of observed healthy population whereas mean for FVC was not significant $(\mathrm{p}=0.158)($ Table 2$)$.

The $\mathrm{FEV}_{1}, \mathrm{FVC}$ and $\% \mathrm{FEV}_{1} / \mathrm{FVC}$ were further analyzed to find out the association with demographic and occupational exposure according to smoking status as presented in Table 3. As expected, age, height and BMI were the important determinants of lung function values. Results for smokers were different from those of non-smokers. Level of dustiness was negatively associated with both $\mathrm{FVC}$ and $\mathrm{FEV}_{1} / \mathrm{FVC}$. However, no effect was found for $\mathrm{FEV}_{1}$. Smoking effect was detected on $\mathrm{FEV}_{1}$ only. On the other hand, when restricted to nonsmokers, the effect of past respiratory illnesses significantly reduced the $\% \mathrm{FEV}_{1} / \mathrm{FVC}$. 


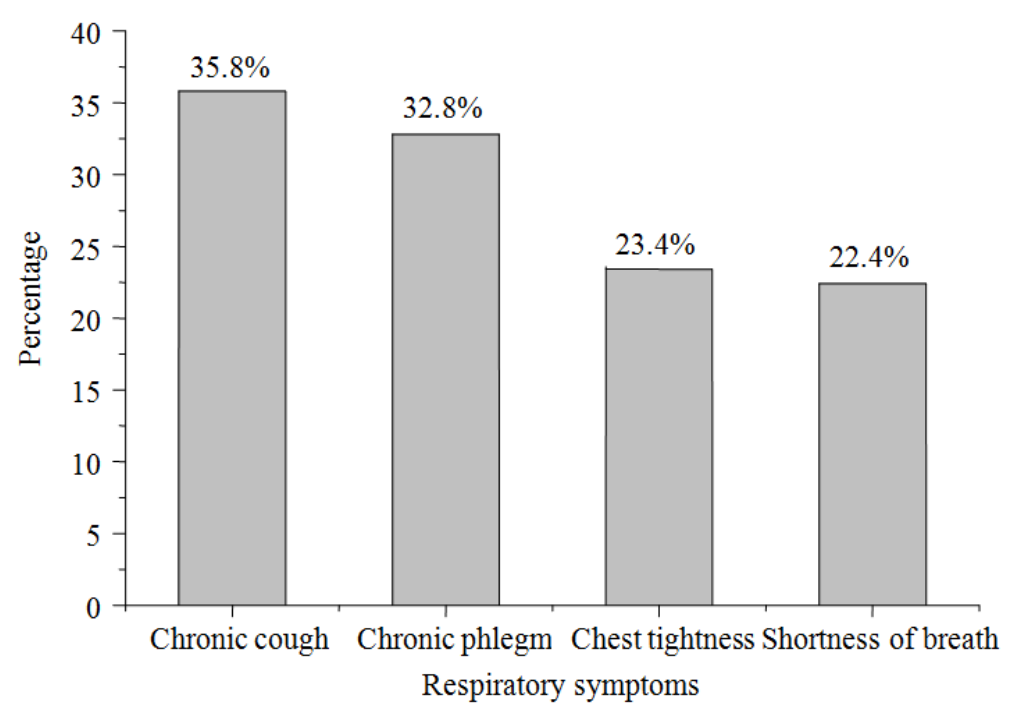

Fig. 1. The distribution of symptoms experienced by workers

\section{Discussion}

\section{Respiratory Symptoms}

Chronic cough appeared to be the most common symptoms and was associated with age. Those who were more than 40 years old have 1.7 times the risk of chronic cough. The second most symptoms was chronic phlegm and was associated with duration of work while the less reported symptoms was shortness of breath and was associated with smoking. Those who had worked for more than 10 years are 1.6 times likely to report the chronic phlegm. Current smokers have 1.8 times risk of reporting shortness of breath as compared to noncurrent smokers. However, chest of tightness was not associated with all the factors. Similar findings were reported by few researchers. Smokers have higher risk of morning cough and morning phlegm (Razlan et al., 2000). The older workers and those working for many years have higher risk of reporting shortness of breath and chest tightness, morning cough and morning phlegm (Razlan et al., 2000; 2002; Nurul et al., 2014). Level of dustiness was not associated with all the reported respiratory symptoms. In contrast, some researchers reported that air pollution in the workplace was significantly associated with cough (Rafiei et al., 2009) and reduced the respiratory function of the workers (Nezhad and Siahkuhian, 2012).

High smoking prevalence $(54.2 \%)$ was also likely to explain the high prevalence of respiratory symptoms. Earlier studies documented that smoking prevalence among steel workers were $65.7 \%$ (Nurul et al., 2005) and $65.0 \%$ (Azlihanis et al., 2006). Smoking was found to be independently associated with shortness of breath. Liou et al. (1996) documented no significant different in the prevalence of respiratory symptoms between smokers and non-smokers, although respiratory symptoms of cough and chronic phlegm appeared to be higher among smokers. Kachel (2002) revealed a significant relation of respiratory symptoms and bronchial obstruction with smoking whereas current smokers were more susceptible to the effects of occupational exposure.

Current smokers appeared to be more susceptible to the effects of occupational exposure. Garshick et al. (1996) reported that occupational exposure was associated with chronic bronchitis and pulmonary function, while effects of smoking on chronic bronchitis and respiratory symptoms were usually additive. The occurrence of respiratory symptoms may represent the earlier response to dust exposure followed by lung function changes. Early respiratory symptoms have been suggested as risk factors for subsequent loss of pulmonary function in steel workers (Abdel-Rasoul et al., 2009; Kayhan et al., 2013; Singh et al., 2013). Respiratory symptoms reflecting airway inflammation resulting from dust, even occurring early and reversibly, have a 'lagged effects' on subsequent pulmonary function. The above authors suggested that workers who developed respiratory symptoms at the early stage are more susceptible to subsequent pulmonary function loss.

\section{Lung Function}

The lung functions were significantly reduced but $\mathrm{FEV}_{1}$ and $\% \mathrm{FEV}_{1} / \mathrm{FVC}$ were found to be significant when compared to Malaysian healthy population standard. Local researchers also found that working population exposed to organic and inorganic dust, such as rice millers (Razlan et al., 2000) and quarry workers (Razlan et al., 2002) had lower lung functions as compared to healthy population. Another studies were 
conducted in an automotive industry (Azlihanis et al., 2007), textiles (Azlihanis et al., 2005) and rice mills (Nurul et al., 2005) also documented decline of lung function due to respiratory symptoms reported among the studied population.

These studies, however, failed to reveal a clear picture of obstructive and restrictive impairments and the relationship with duration of exposure as suggested in other studies. This might be due to the inadequate findings of lung function abnormalities as chest x-ray and radiological opacities were not examined. Large range of duration of employment can provide significant results for both pattern of lung function.

Duration of employment was associated with decrease in all lung function indices and more pronounced in $\% \mathrm{FEV}_{1} / \mathrm{FVC}$. This finding was in line with previous studies. Chen et al. (2006) reported that increased duration of employment was associated with significant decrease of pulmonary function. Ulvestad et al. (2001) revealed significant decrease in $\mathrm{FEV}_{1}$ and $\mathrm{FVC}$ related to years of exposure. Increasing working years was also related to decreasing annual decline in $\mathrm{FEV}_{1}$ among silicon carbide industry workers (Johnsen et al., 2013).

The multiple linear regression analysis of the lung function values showed a clear dose-response effect for level of dustiness in the smokers. The lower $\mathrm{FEV}_{1} / \mathrm{FVC}$ in smokers was probably achieved at lower expiratory volume in first second compared with its vital capacity. There was an effect on cigarette smoking with increasing cigarette equivalent was associated in reducing $\mathrm{FEV}_{1}$ as well as FVC. Chen et al. (2006) found a deteriorating effect of respirable dust exposure on $\mathrm{FVC} \%$ in current smokers than those workers who did not smoke at all. However, the effect of $\mathrm{FEV}_{1} / \mathrm{FVC}$ cannot be seen in this model. Smoking was the strongest confounder in all respiratory outcomes and it has been hard to separate the specific effects of occupational exposures from smoking effects among the populations. In practice it is not often feasible to recruit sufficient numbers of workers who are lifelong-workers.

Earlier studies reported various findings of lung functions impairments among steel workers. Bala and Tabaku (2010) found that COPD prevalence and its symptoms were high and a strong correlation between occupational area, air pollution and the possibility for developing COPD. In another cross-sectional study, exposure to dusts in steel workers has also been strongly associated with reductions in $\mathrm{FVC}, \mathrm{FEV}_{1}$ and $\mathrm{FEV}_{1} / \mathrm{FVC} \%$. Significant decreases in $\mathrm{FEV}_{1}$ and $\mathrm{FVC}$ have been associated with increases in occupational exposures to gases and fumes (Xu et al., 1992). Gomes et al. (2001) reported that exposure to dusts are strongly associated with reductions in Forced Vital Capacity (FVC), $\mathrm{FEV}_{1}$ and $\% \mathrm{FEV}_{1} / \mathrm{FVC}$. Combined occupational exposures to dusts and gases and fumes have been reported to reduce Peak Expiratory Flow rate (PEF) (Pham et al., 1979; Wang et al., 1996).

Particles formed when the molten metal solidifies in the air due to the temperature gradient outside the furnace. Without proper protective equipment, these particles are easily inhaled, reaching the alveoli and damaging the respiratory function. Frequency of using mask was found to have a positive relationship with FVC. However, compliance to Personal Protective Equipment (PPE) especially usage of mask was low and being ignored, only $34.3 \%$ of workers were frequently using mask during the working period. Therefore, respiratory health hazard risk along with the other health risks was quite obvious. It was also reported that they have option for an over time of 3-4 h per day. These revealed that these workers were exposed to hazardous condition for 60-72 h per week without proper PPEs. Adherence to the use of PPE can minimize the health hazards by increasing life expectancy and productivity of the workers (WHO, 2009).

Past respiratory illnesses increase the lung function impairment independently from the effect of smoking. Progression of disease may be caused by long term effect of occupational exposure. Therefore, medical doctors and health policy makers should handle the potential causes and consequences of COPD as well as introducing working ambient air-safety protection.

\section{Limitation of the Study}

This study was limited as it did not measure the actual dust concentration. Dust sampling would differ on an objective basis while the experience of the workers would limit their ability to classify the exposure correctly. Thus, dust exposure measurement especially the respirable fraction needs to be assessed instead of subjective indicators by questionnaire to detect a respiratory ill effect. The composition of dust exposure as well as particle size and concentration contributed primarily to the effect.

The examinations (this study and most of the previous investigations) were conducted at one point in time on active workers during active employment. Studies on currently employed workers might be subjected to selection bias. The subjects who were involved in this study might have suffered less from their exposure (could be a result of better preventive measures) than others who have left their employment, some possibly for reasons of ill health sustained from their job exposure. $\mathrm{Ng}$ and Chan (1992) included retired workers as well as active workers found that retired/resigned workers had higher prevalence of lung abnormalities and also had lower mean of $\mathrm{FEV}_{1}$ and FVC after adjustment for age, height and pack-years of cigarette had been done. 


\section{Conclusion}

Lung function test revealed some degree of impairment as compared to healthy population and smoking had an additive effect on respiratory health. Encouragement of smoking cessation, occupational health education to reduce the dust exposure and using protective mask during working period and periodical medical examinations are needed to reduce the respiratory impairment. Further extensive epidemiological and pathological studies among studied population are strongly recommended for the health and safety of the steel workers.

\section{Acknowledgement}

We were grateful with the cooperation of all participating workers. Special thanks go to the management of Safety Health and Environment department especially to Dr Mohd Abd Rashid bin Hussin and Miss Nurul Atikah Che Hassan for their assistance throughout the data collection. This research was supported by the UKMMC research grant project number FF-055-2013.

\section{Funding Information}

This article was funded by the UKM Medical Centre; project No FF-055-2013. The funder had no role in study design, data collection and analysis, decision to publish, or preparation of the manuscript.

\section{Author's Contribution}

Nurul Ainun Hamzah: Designed the research plan and organized the study, data collection of the study sample, analysis and writing of the manuscript.

Shamsul Bahri Mohd Tamrin: Statistical analysis and contributed to the writing of the manuscript.

Noor Hassim Ismail: Designed the research plan, organized the study, contributed to the statistical analysis and writing of the manuscript.

\section{Ethics}

This article is original and contains unpublished material. The corresponding author confirms that all of other authors have read and approved the manuscript and no ethical issues were involved.

\section{References}

Abdel-Rasoul, G., O.A.E. Mahrous, M.E. Abou Salem, M.A. Al-Batanony and H.K. llam, 2009. Auditory and respiratory health disorders among workers in an iron and steel factory. Zagazig. J. Occup. Health Safety, 2: 1-10. DOI: 10.4314/zjohs.v2i1.45968
Azlihanis, A.H., A. Mazlan, A.M. Aziah, A.H. Zainul and M. Razlan et al., 2005. Relationship of respiratory symptoms and pulmonary function among workers in garment factory. Malaysian J. Public Health Med., 5: 33-33.

Azlihanis, A.H., A. Mazlan, M. Razlan and A.H. Nurul, 2006. The association of lung function and smoking among workers in a steel industry. Malaysian J. Commun. Health, 12: 10-10.

Azlihanis, A.H., A. Mazlan, M. Razlan, A.H. Nurul and A. Azwan et al., 2007. A respiratory health survey among male workers in an automotive manufacturing plant in Perak. Malaysian J. Med. Sci., 14: 289-289.

Azwan, A., A. Mazlan, S.M. Nasir, A.H. Azlihanis and H. Zulfazli et al., 2006. The relationship of respiratory symptoms and lung function status among workers in steel plant. J. Commun. Health, 12: $24-24$.

Bala, S. and A. Tabaku, 2010. Chronic obstructive pulmonary disease in iron-steel and ferrochrome industry workers. Cent. Eur. J. Public Health, 18: 93-98. PMID: 20939259

Bogadi-Šare, A., 1990. Respiratory disorders in stainless steel workers. Arh. Hig. Rada. Toksikol., 41: 249-255. PMID: 2281960

Chen, P.C., P.E. Doyle and J.D. Wang, 2006. Respirable dust exposure and respiratory health in male Taiwanese steelworkers. Ind. Health, 44: 190-199. PMID: 16610559

Garshick, E., M. Schenker and J.A. Dosman, 1996. Occupationally induced airways obstruction. Med. Clin. North Am., 80: 851-878. PMID: 8676617

Gomes, J., O.L. Lloyd, N.J. Norman and P. Pahwa, 2001. Dust exposure and impairment of lung function at a small iron foundry in a rapidly developing country. Occup. Environ. Med., 58: 656652. PMID: 11555687

Huvinen, M. and E. Pukkala, 2013. Cancer incidence among Finnish ferrochromium and stainless steel production workers in 1967-2011: A cohort study. Brit. Med. J., 3: e003819-e003819. DOI: 10.1136/bmjopen-2013-003819

Johnsen, H.L., M.D. Bugge, S. Føreland, H. Kjuus and J. Kongerud et al., 2013. Dust exposure is associated with increased lung function loss among workers in the Norwegian silicon carbide industry. Occup. Environ. Med., 70: 803-809. PMID: 23852098

Johnson, A., C.Y. Moira, L. MacLean, E. Atkins and A. Dybuncio et al., 1985. Respiratory abnormalities among workers in an iron and steel foundry. Brit. J. Ind. Med., 42: 94-100. PMID: 2982392

Kachel, T., 2002. Effect of occupational exposure and smoking on spirometric tests and symptoms of chronic bronchitis. Pneumonol. Alergol. Pol., 71: 428-439. PMID: 15052979 
Kayhan, S., U. Tutar, H. Cinarka, A. Gumus and N. Koksal, 2013. Prevalence of occupational asthma and respiratory symptoms in foundry workers. Pulmonary Med., DOI: 10.1155/2013/370138

Kolarzyk, E., M. Stepniewski and I. Zapolaska, 2000. Occurrence of pulmonary diseases in steel mill workers. Int. J. Occup. Med. Env. Heal, 13: 103-112. PMID: 10967840

Liou, S.H., S.Y., Cheng, F.M. Lai and J.L. Yang, 1996. Respiratory symptoms and pulmonary function in mill workers exposed to wood dust. Am. J. Ind. Med., 30: 293-299. PMID: 8876797

MRC, 1966. Questionnaire on respiratory symptoms. Medical Research Council

Nezhad, M.H.M. and M. Siahkuhian, 2012. The effect of air pollution on cardio-respiratory fitness of steel plant co.workers. Middle-East J. Sci. Res., 11: 225-229.

Ng, T.P. and S.L. Chan, 1992. Lung function in relation to silicosis and silica exposure in granite workers. Eur. Respir. J., 5: 986-991. PMID: 1330677

Nurul, A.H., A. Mazlan, M. Razlan, N. Rusli and L. Naing et al., 2006. Respiratory symptoms and pulmonary function among male steel workers in Terengganu. J. Commun. Health, 12: 52-52.

Nurul, A.H., A.H. Azlihanis, A. Mazlan, A.M. Aziah and A.H. Zainul et al., 2005. The effects of smoking on lung function among workers in a steel factory. Malaysian J. Public Health Med., 5: 56-56.

Nurul, A.H., B.M.T. Shamsul and I.N. Hassim, 2014. Respiratory symptoms and pulmonary function among male steel workers in Terengganu, Malaysia. Malaysian J. Public Health Med., 14: 10-18.

Pham, Q., G. Mastrangelo, N. Chau and J. Haluszka, 1979. Five year longitudinal comparison of respiratory symptoms and function in steelworkers and unexposed workers. B Eur. Physiopath. Res., 15: 469-480.

Rafiei, M., A.S. Gadgil, S.D. Sore, N. Jaafarzadeh and R. Mirkazemi, 2009. Assessment of air pollution and its effects on the health status of the workers in beam rolling mills factory (Iran National Steel Industrial Group) from Ahvaz-Iran. Ind. J. Occup. Environ. Med., 13: 20-22.

DOI: $10.4103 / 0019-5278.50719$
Razlan, M., L. Naing, A. Zulkifli and Y. Kamarul, 2000. Respiratory health of rice millers in Kelantan, Malaysia. Southeast Asian J. Trop. Med. Public Health, 3: 575-578. PMID: 11289024

Razlan, M., L. Naing, A. Zulkifli and N. Rusli, 2002. Respiratory symptoms and pulmonary function among male quarry workers in Kelantan, Malaysia. Malaysian J. Public Health Med., 2: 54-57.

Singh, P.L., A. Bhardwaj and K.K. Deepak, 2013. Occupational exposure to respirable suspended particulate matter and lung functions deterioration among steel workers: An exploratory study in India. ISRN Public Health. DOI: 10.1155/2013/325410

Singh, R., H.J. Singh and R.G. Sirisinghe, 1993. Spirometric studies in Malaysians between 13 and 69 years of age. Med. J. Malaysia, 48: 175-184. PMID: 8350793

Ulvestad, B., B. Bakke, W. Eduard, J. Konrerud and M.B. Lund, 2001. Cumulative exposure to dust causes accelerated decline in lung function in tunnel workers. Occup. Environ. Med., 58: 663-669. PMID: 11555688

Wang, M.L., L. McCabe, J.L. Hankison, M.H. Shamssain and E. Gunel et al., 1996. Longitudinal and cross-sectional analyses of lung function in steelworkers. Am. J. Respir. Crit. Care Med., 153: 1907-1913. PMID: 8665054

WHO, 2009. Epidemiological of work-related diseases and accidents: Technical report series. Geneva, 778: 8-10.

Xu, X., D.C. Christiani, D.W. Dockery and L. Wang, 1992. Exposure-response relationships between occupational exposures and chronic respiratory illness: A community-based study. Am. Rev. Respir. Dis., 146: 413-418. PMID: 1489133 